\title{
REVISTAS MASCULINAS. ANÁLISIS CRÍTICO DE 8 CABECERAS: TENDENCIAS SOCIALES, PUBLICIDAD, VALORES
}

\section{MEN'S MAGAZINES. CRITICAL ANALYSIS OF 8 HEADINGS: SOCIAL TRENDS, ADVERTISING, VALUES}

Maribel Martínez Eder: Portavoz de FIATYR (Federación Ibérica de Telespectadores y Radioyentes) mm.eder@asociacionplazadelcastillo.org

\section{CURRÍCULUM VITAE}

Fundadora y presidenta de la Asociación Plaza del Castillo ATR Navarra de Usuarios de Medios de Comunicación, integrante de FIATYR (Federación Ibérica de Asociaciones de Telespectadores y Radioyentes). Fue miembro del Consejo Asesor de RTVE en Navarra.

\section{RESUMEN}

Análisis de diferentes revistas masculinas, DT, FHM, GQ, MAN, Men's Health, NOX, Primera Línea y Vanity Gay, para valorar sus elementos formales y estéticos, pero principalmente para sacar conclusiones acerca de las tendencias sociales, la publicidad y los valores que en ellas se muestran. Son productos muy atractivos visualmente, dirigidos cada uno a segmentos específicos de edad, con una presencia altísima de la imagen de la mujer con una gran carga sexual. Éstas son algunas de las conclusiones obtenidas tras el estudio que se incluyen en el texto. 


\title{
PALABRAS CLAVE
}

Revistas masculinas - Publicidad - Mujer - Valores

\begin{abstract}
Analysis of different men's magazines, DT, FHM, GQ, MAN, Men's Health, NOX, First Line and Vanity Gay, to assess their formal and aesthetic elements, but mainly to draw conclusions about the social, advertising and values ??in them is. They are visually attractive products, each aimed at specific segments of age, with a high presence of the image of women with a sexual charge. Here are some of the conclusions reached after the study included in the text.
\end{abstract}

\section{KEY WORDS}

Men's magazines - Advertising - Women - Values

\section{TEXTO}

La Asociación Plaza del Castillo de Usuarios de Medios de Comunicación se complace en informarle que ya puede consultarse, en su página web (http://www.asociacionplazadelcastillo.org/), el informe "Revistas masculinas. Análisis crítico de 8 cabeceras: tendencias sociales, publicidad, valores". Este trabajo de 47 páginas, elaborado en colaboración con el Servicio de Consumo del Gobierno de Navarra, se enmarca en nuestro programa de actividades del presente año, estando fechado en el pasado mes de julio. 
Las cabeceras analizadas en este trabajo son: DT, FHM, GQ, MAN, Men'sHealth, NOX, Primera Línea y Vanity Gay.

Además de una breve valoración de sus elementos formales y estéticos, el trabajo contempla otros aspectos fundamentales: incidencia de la publicidad; franjas de edad y sectores destinatarios; filosofía base de sus contenidos; análisis y crítica de la imagen y modelos femeninos propuestos; "canales de comunicación" existentes entre estas publicaciones y sus lectores; rol cultural.

Anticipamos, muy brevemente, algunas de las conclusiones generales:

- Son productos muy atractivos visualmente que priman los aspectos gráficos sobre los contenidos escritos; y de precios muy asequibles.

- Cada una de ellas está dirigida, preferentemente, a segmentos de edad y capacidad adquisitiva concretas; en cualquier caso, varones sin cargas familiares.

- El peso de la publicidad, análoga en casi todas ellas, ya sea directa o indirecta en sus diversas presentaciones, alcanza de media el 48’1 \% de sus espacios. Más parecen catálogos que revistas "clásicas".

- La omnipresente imagen de la mujer presenta una alta carga sexual: envuelta en mucho glamour y luciendo magníficas curvas. Una mujer que se manifiesta pragmática, joven, bellísima, sofisticada, en perfecto estado de revista; y a la que hay que conquistar y complacer (en particular, sexualmente). Pero, por contra, casi nunca se habla de cultivar relaciones estables de pareja. 
- La política de comunicación con los lectores es unidireccional -de la redacción al lector- y dirigista.

- Difunden una "cultura" individualista de la calidad de vida y del ocio; constituyendo magníficos instrumentos para pasar un rato agradable y "ponerse al día" en marcas comerciales, tendencias estéticas, y servicios diversos.

- Mentalidad que destilan: consumismo, hedonismo, relativismo... y con mucho glamour; siempre que se maneje pasta, claro. Todo, "políticamente muy correcto". Y sin asomo de crítica social. Mera distracción, pues.

- Son productos "globales" que apenas recogen la propia idiosincrasia cultural, con contenidos análogos a los que pueden encontrarse en naciones muy alejadas de la nuestra.

En definitiva, proclaman: "gustarse para gustar", "vive al día y deja vivir", "disfruta de tu cuerpo... y del ajeno", "todo tiene un precio", "las marcas sí importan", "tú decides, nadie más".

Deseamos que el trabajo sea de su interés.

Pamplona, 9 de agosto de 2007 